|| ISSN(online): 2589-8698 || ISSN(print): 2589-868X || International Journal of Medical and Biomedical Studies

Available Online at www.ijmbs.info

PubMed (National Library of Medicine ID: 101738825)

Index Copernicus Value 2018: 75.71

Volume 3, Issue 4; April: 2019; Page No. 242-244

\title{
CADAVERIC ANATOMY AND RELATIONSHIP OF PHRENIC NERVE AND SUBCLAVIAN VEIN
}

Dr. Sandeep Madaan ${ }^{1}$, Dr. Lavlesh Mittal ${ }^{2}$

${ }^{1}$ Assistant Professor Dept. of Anatomy K.M. Medical College and Hospital, Mathura (UP).

${ }^{2}$ Assistant Professor Dept. of Anatomy K.M. Medical College and Hospital, Mathura (UP).

Article Info: Received 10 April 2019; Accepted 28 April. 2019

Cite this article as: Madaan, D. S., \& Mittal, D. L. (2019). CADAVERIC ANATOMY AND RELATIONSHIP OF PHRENIC NERVE AND SUBCLAVIAN VEIN. International Journal of Medical and Biomedical Studies, 3(4).

DOI: https://doi.org/10.32553/ijmbs.v3i4.788

Address for Correspondence: Dr. Lavlesh Mittal, Assistant Professor Dept. of Anatomy, K.M. Medical College and Hospital, Mathura (UP).

Conflict of interest: No conflict of interest.

\section{Abstract}

Introduction: Deep knowledge of anatomy is an essential part of surgical practice. Students of medical sciences gain knowledge and theoretical data through actual visualization of anatomic structures of the cadavers also anatomic relations can be studied more efficiently by practicing on cadavers. As phrenic nerve may be damaged during subclavian vein catheterization the relationship between the phrenic nerve and the subclavian vein is of clinical interest. During the subclavian vein catheterization analogous variable relationships are helpful to explain and prevent damage to the phrenic nerve.

Material and Methods: Dissection was started from the root of the neck. No surgical scars, gross anatomical and morphological abnormalities was noted on the cadaver. Measurements were taken during the anatomical dissections.

Results: Of the 36 cadavers dissected in $34(94.44 \%)$ cases phrenic nerve was found posterior to the subclavian vein and in $2(5.56 \%)$ cases found anterior to the subclavian vein of which one case was male and the other was female. In the male case in which phrenic nerve was passing anterior to the subclavian vein, it was adherent to the anterior wall of the subclavian vein and was nor piercing the vein wall.

Conclusion: The cannulating needle may damage the phrenic nerve which is adherent to the subclavian vein. So, the puncture site should be more laterally at the outermost portion of the subclavian vein. Anatomical variants during invasive practical procedures should be always kept in mind.

Keywords: phrenic nerve, subclavian vein, phrenic nerve palsy, catheterization.

\section{Introduction:}

Deep knowledge of anatomy is an essential part of surgical practice.the main teaching modality in anatomy education was cadaveric which was introducedin the ancient times. From the viewpoint of anatomy and physiology In the $3^{\text {rd }}$ century $A D$, the first human cadaveric dissections were performed in Greece by Herophilus of Chalcedon and Erasistratus of Chios to understand the whole body. However, religious and moral attitudes and taboos towards physicians and medical schools had many detrimental effects on the scientific value of cadaver-based education.Studentsof medical sciences gain knowledge and theoretical data through actual visualization of anatomic structures of the cadavers also anatomic relations can be studied more efficientlyby practicing on cadaversii.
As phrenic nerve may be damaged during subclavian vein catheterization the relationship between the phrenic nerve and the subclavian vein is of clinical interestiii. The phrenic nerve usually enters the thoracic cavity posterior to the subclavian vein ${ }^{\text {iv }}$. The terminal branches of phrenic nerve pierce the diaphragm and travel on the abdominal surface of the diaphragm supplying the parietal peritoneum through connections with branches of celiac plexus ${ }^{v}$. During the subclavian vein catheterizationanalogous variable relationships are helpful to explain and prevent damage to the phrenic nerve.

\section{Material and Methods:}

Present study was carried out in the department of Anatomy in K.M. Medical College and Hospital, Mathura (UP). During dissection of 36 cadavers, 25 male and 11 female we found the topographical 
relationship of the subclavian vein and the phrenic nerve at the thoracic outlet. Dissection was started from the root of the neck. Nosurgical scars, gross anatomical and morphological abnormalities was noted on the cadaver. Measurements were takenduring the anatomical dissections.

\section{Results:}

36 cadavers dissected in 34 (94.44\%) casesphrenic nerve was found posterior to the subclavian vein and in $2(5.56 \%)$ cases found anterior to the subclavian vein of which one case was male and the other was female. In the male case in which phrenic nerve was passing anterior to the subclavian vein, it was adherent to the anterior wall of the subclavian vein and was nor piercing the vein wall.

\section{Discussion and Conclusion:}

The phrenic nerve is sole motor supply to the corresponding half of thediaphragm, and it sends afferent fibres from the diaphragm, pericardium, pleura, and peritoneum ${ }^{\mathrm{vi}}$.

Commonly phrenic nerve arises from the $4^{\text {th }}$ cervical root with occasional contributions from $3 \mathrm{rd}$ and $5^{\text {th }}$ cervical root. It almost descends vertically on the anterior surface of the anterior scalene muscle, posterior to the pre-vertebral fascia. Then, it crosses anterior to the first portion of the subclavian artery posterior to the subclavian vein and enters the thorax by intersecting anteromedially to the internal thoracic artery. Each nerve lies in the thorax in contact with the mediastinal pleura throughout its course towards the diaphragm.

It is observed that in $\mathbf{4}-\mathbf{3 5 \%}$ of the cases subclavian vein catheterization can cause complications like haemothorax, pneumothorax, mediastinal haematoma, cannulation of the subclavian artery, brachial plexus injury, thrombophlebitis, air embolism, injury to the recurrent laryngeal nerve, erosion of catheter, and phrenic nerve injury. Phrenic nerve injury can be immediate as well as there can be late complications causing phrenic nerve palsy ${ }^{\text {vii }}$.

Also it is shown that accessory phrenic nerve (APN) describing the nerve to subclavius as the major origin of the APN viii. Alos it was reported that an APN was associated with 99 of the phrenic nerve $(61.8 \%)$, with bilateral occurrence in 31 cadavers (38.8\%). Bilateral symmetrical origin of the APN, from the nerve to subclavius, was observed in 10 cadavers $^{\mathrm{ix}}$.
Cadaveric dissection is important in improving surgical and technical knowledge for surgery residents. Detailed practice dissection of surgical procedures prior to live patient operations, increasesthe confidence levels and surgical skills ${ }^{x}$.

There can be compression of the phrenic nerve by the rigid tip of the venous catheter without perforating the subclavian vein can occur ${ }^{\mathrm{xi}}$ and Phrenic nerve palsy generally represents an immediate complication of subclavian venepuncture ${ }^{\mathrm{xii}}$. Also, large needle size and repeated attempts are predominant factor for more severe nerve injury ${ }^{\text {xiii. }}$.

An accessory phrenic nerve is present in about $61.8 \%$ to $75 \%$ of the people ${ }^{\mathrm{xiv}}$. Loukas et $\mathrm{a}^{\mathrm{xv}} \mathrm{l}$ in their study reported that in $45 \%$ cases, the loop between the phrenic and accessory phrenic nerve involved the subclavian vein.Codesido and Guerri-Gutenberg reported a case of accessory phrenic nerve passing through an annulus of the subclavian vein located 1 $\mathrm{cm}$ away from the jugulosubclavian junction ${ }^{\mathrm{xvi}}$.

In our study of 36 cadavers, 34 (94.44\%) cases phrenic nerve was found posterior to the subclavian vein and in 2(5.56\%) cases found anterior to the subclavian vein of which one case was male and the other was female. In the male case in which phrenic nerve was passing anterior to the subclavian vein, it was adherent to the anterior wall of the subclavian vein.

The cannulating needle may damage the phrenic nerve which is adherent to the subclavian vein. So, the puncture site should be more laterally at the outermost portion of the subclavian vein. Anatomical variants during invasive practical procedures should be always kept in mind.

\section{References:}

1. Ghosh SK. Human cadaveric dissection: a historical account from ancient Greece to the modern era.Anat Cell Biol. 2015 Sep; 48(3):153-69.

2. Nwachukwu C, Lachman N, Pawlina W. Evaluating dissection in the gross anatomy course: Correlation between quality of laboratory dissection and students' outcomes.Anat Sci Educ. 2015 Jan-Feb; 8(1):45-52.

3. Aggarwal S, Hari P, Bagga A, Mehta SN. Phrenic nerve palsy: a rare complication of indwelling subclavian vein catheter. PediatrNephrol 2000; 14: 203-4 
4. Williams PL, Bannister LH, Berry MM, et al. Gray's Anatomy, 38th Edn. Edinburgh: Churchill Livingstone, 1995; 1265-6

5. Natsis K, Paraskevas G, Papaziogas B, Agiabasis A. 'Pes anserinus' of the right phrenic nerve innervating the serous membrane of the liver: a case report. Morphologie 2004; 88: 203 -5

6. Basmajian JV. Grant's Method of Anatomy, 8th Edn. Baltimore: Williams \& Wilkins, 1971; $434-7$

7. Rigg A, Hughes $P$, Lopez A, Filshie A, Cunningham $D$, Green $\mathrm{M}$. Right phrenic nerve palsy as a complication of indwelling central venous catheters. Thorax 1997; 52: $831-3$

8. Clemente $C D$, ed. The peripheral nervous system. Chapter 12: spinal nerves. Gray's anatomy, 30th ed. Baltimore: Williams \& Wilkins; 1985:1085,1223-25

9. Marios Loukas, Christopher R. Kinsella, Robert G. Louis, Sagar Gandhi,Brian Curry. Surgical Anatomy of the Accessory Phrenic Nerve. Ann ThoracSurg2006; 82:1875

10. Kim SC, Fisher JG, Delman KA, Hinman JM, Srinivasan JK. Cadaver-Based Simulation Increases Resident Confidence, Initial Exposure to Fundamental Techniques, and May Augment Operative Autonomy.J Surg Educ. 2016 Nov - Dec; 73(6):e33-e41.

11. Takasaki $Y$, Arai T. Transient right phrenic nerve palsy associated with central venous catheterization. $\mathrm{Br} J$ Anaesth 2001; 87: 510-1

12. Hadeed HA, Braun TW. Paralysis of the right hemidiaphragm as a complication of internal jugular cannulation: report of a case. J Oral MaxillofacSurg 1998; 46: 409-11

13. Steinfeldt $T$, Nimphius $W$, Werner $T$, et al. Nerve injury by needle nerve perforation in regional anaesthesia: does size matter? Br J Anaesth 2010; 104: $245-53$

14. Bergman RA, Thompson SA, Afifi AK, Saadeh FA. Compendium of Human Anatomic Variation. Baltimore: Urban \& Schwarzenberg, 1988; 138-9

15. Loukas M, Kinsella CR, Louis RG, Gandhi S, Curry B. Surgical anatomy of the accessory phrenic nerve. Ann ThoracSurg 2006; 82: 1870-5

16. Codesido $M$, Guerri-Gutenberg RA. Right accessory phrenic nerve passing through an annulus of the subclavian vein. Clin Anat 2008; 21 : 779-80 